\title{
DEFINING FRIENDSHIP: AN AGE OLD QUESTION V0.75
}

\author{
CHRISTIAN LANGKAMP
}

\begin{abstract}
This paper uses a dataset generated from keyword tagging works of literature and contemporary sources to scope the potential of a common definition and understanding of friendship. About 10000 keyword tags on about 300 keywords are used to extract friendship definitions from authors such as Aristotle, Cicero, C.S. Lewis, Alberoni, Nehamas, Greif, Degges-White, Hall, Shumway, Millington and others. On the compiled dataset MDS and correlational analysis is used to validate intuitive groupings and relatedness of friendship concepts. Six key dimensions of friendship are deduced with 55 subtraits.

As an application a relative importance of friendship traits in old age is deduced. The paper is still work in progress but now at a stage to solicit discussion and comments.

https://advance.sagepub.com/articles/Defining_Friendship_An_Age_0ld_. Question/12721376/1
\end{abstract}

\section{INTRODUCTION}

Friendship is an age old topic. The first recorded story of mankind, Gilgamesh and Enkidu, essentially is about friendship. The Greeks, most notably Plato, Aristotle and Epicurus, and the Romans (Cicero) discussed its nature and its effect.

In the 20th century sociologists and psychologists started studying the concept of friendship, whether more its nature and effects within the pair or dyad, or what impact it has on networks and how people move within society and networks. Theories on Social Penetration theory and Social Exchange theory have been formulated and tested. Whereas however sociologists and psychologists clamour about the loss of meaning of 'friend' given todays superficiality and Facebook, equally the supposedly more meaningful term 'friendship' classifying the relationship that two 'true' friends have towards each other is by no means even close to uniformly agreed upon. Indeed even linguistically classical philosophers, psychologists and sociologists can be shown to occupy different spheres. Even in 2020 it seems that the criticism of Fischer, 1982 on the inadequacy of the various definitions available does still hold. Fischer, 1982 , p.288 defines the task at hand thus: "These observations lead to the conclusion that 'friend' is probably too vague a concept to be used in scientific research. We cannot, however, abandon it. It is too important a 'folk concept', an idea that people use to order their worlds. And, it is too much a part of our own intellectual apparatus. But we should at least have a systematic, empirical understanding of what Americans seem to mean when they call someone a friend." Matthews, 1986 likewise criticises the inadequacy and partiality of focus of various friendship definitions in sociological and psychological literature prior to her exploration of friendship in old age.

This paper tries to measure and contrast the associations and emphases that writers of old and new place on the concept of friendship. It intends to thus answer then question by simply generating a data set rather than fine arguments along philosophical or logical lines, and likewise staying with simple data rather than indulging in highly sophisticated statistics analysing carefully crafted sociological surveys.

The focus at the moment is getting the overall view and dimensionality of friendship right. This document is designed to spell things out, and to serve as a discussion basis with other scholars and friends to garner feedback, placing trust in peoples intuition and gut feeling about this feature of basic social life. In terms of vocab and language

Date: March 4, 2021. 
it should thus be understandable to a well-read lay person, but not necessitating familiarity with specialist psychological and sociological vocabulary.

The content of this paper is to define a conceptual framework that captures the key elements of friendship attitude and behaviour with a set of variables reasonably completely and concrete enough, that it resonates with lay peoples experience and understanding. It tries to evaluate whether there is a consensus view on friendship and explore to what degree divergence exists across disciplines, target audience, gender and other

\section{Literature Review - Source material}

When reviewing the preeminent works on friendship, the following works come to mind. Aristotle, 1926 with his Nikomachean ethics and the classification of friends of utility, pleasure and virtue is quoted and discussed usually at length in any text on friendship. Likewise many classically minded people cite his requirements of goodwill that is reciprocally declared and demonstrated. Cicero, 1923, discussing the role of friendship on the back of breaking friendship and allegiances during the Roman Civil war, however deserves no less attention. In our time continuing the classical tradition of discussing the nature of friendship there is the Oxford Inkling Lewis, 1960 , normally known for apologetic writings on Christianity and the Chronicles of Narnia, Alberoni, 2016 - an Italian intellectual most prolific in the 70ies - and Princeton philosopher Nehamas, 2016 generally concerned with translating what a philosophically good life could mean in our century. On the psychological / sociological pop science literature (i.e. books that are based on solid research however designed to be read by a wide public) there is Degges-White and Borzumato-Gainey, 2011 on female friendship, Greif, 2009 on male friendship, and Delaney and Madigan, 2017 on friendship among modern adolescents. Shumway, 2018 and Millington, 2019 published densely packed friendship improvement advice, even labelling their book identically as the Friendship Formula. Asatryan, 2016 writes with depth and insight about concrete steps towards improving friendship quality. Nelson, 2016 illustrates the importance of the positivity - consistency - vulnerability framework for female friendships and Nelson, 2020 transfers this framework to working relationships and teams at work. On the religious side, aside from going directly to the Bible, Youtube and SermonCentral has made a number of sermons accessible where pastors urge their flock to build good friendships and give advice on how to go about it. Rath, 2006 on the back of a large dataset from the Gallup organisation identifies eight roles how our friends benefit our lives and how this can particularly unfold at the work place.

Using the internet as resource I found three contributions by Jenna Birch, describing important characteristica of friends according to an MBTI Birch, 2018b, Birch, 2018a, Birch, 2019. Other friendship type explanations from Cerri, 2019 or van Devender, 2020 do the same, giving advice on friendship desirability and compatibility of various personality types. Likewise Youtube has a host of Ted Talks and other video resources where people young and old share their wisdom on the significance of friendship and how to assess their quality. Finally in the general public media opinion pieces on friendship appear regularly, thus the Guardian or the online-blogging platform Medium have friendship channels. The range is truly diverse and it indicates that the associations with the term 'good close friend' or 'friendship' might vary and indeed significantly diverge depending on the value set, age, gender, education, background or other personal attributes and preferences of the person asked.

On the sociological research side, Hall, 2012 conducted a key study on the important features of friendships among undergraduates. Roberts-Griffin, 2011 summarized a survey conducted on the AuthenticHappiness Website of Seligman at UPenn. On adult research, the authors Blieszner and Adams have over three decades been at the center of a long research program looking at friendship among adults and older adults, with Blieszner, Ogletree, and Adams, 2019 providing an intermediate review and quo vadis. Argyle and Henderson, 1984 provide rules of friendship, Oswald, Clark, and Kelly, 2004 provide a factor analysis. Recently Deri et al., 2018 performed a study on 
characteristics of relationships including friends. Apostolou, Keramari, et al., 2020 and Apostolou and Keramari, 2020 generate datasets on motivators and inhibitors for making friends. All this research is done to see if there is structure to the sociological concept of friendship.

\section{Method}

The method to both identify the dimensions as well as generating a full dataset was to treat the various sources on friendship as if they were unstructured interviews in anthropological research. Thus I coded the text with a growing set of keywords 1 , at the time of writing loosely 300 . These key words would generally describe items such as 'my friend does $\mathrm{X}$ with or for or to me' or 'my friend is or has this desirable attribute' or 'my friend exhibits this attitude towards me'. Examples of keyword could be 'Allow Expression of Self' or 'Play Boardgames' or 'Virtuous character' or 'Wants my success'. Thus a text such as Book VIII and IX of the Nikomachean Ethics 250 keywords triggered, other texts would provide between 50 and 500 triggers.

Where sociological analyses such as Hall, 2012 or Roberts-Griffin, 2011 provided tables based on surveys, usually between 100 and 150 keyword tags were used to approximate the relative results and allocate it to the various keywords. The key here was to break it down into line items of surveys and accurately map the question asked, not the concept it was associated. A cut had to be made to restrict to actual friends behaviour or expectations towards them while they are still friends. Once friends become romantic lovers or enemies this behaviour became out of scope and no keyword tags were assigned to descriptors. Then the 300-keyword-tuple or frequency table vector per source is transformed into a uniform 50-tuple per work (see next section for variable description) simply stating to what percentage the work is placing emphasis on the various themes. Figure 1 displays the flow. There is no doubt that substantial subjectivity is embedded in this process, however this is the first round aimed at generation of discussion and generation of a first draft of new categories and process. It also can be questioned to what degree a work such as Book VIII and IX of the Nikomachean ethics or as the l'Amicizia of Alberoni can be adequately reduced to essentially a vector of 50 numbers, but it is a necessary step in order to adequately try to compare the weights placed on the individual concepts.



Figure 1. Example Coding Aristotle

One side result of the coding exercise is an appreciation for the diversity of key words and aspects, that also shows the need to catalogue and codify past questions used in sociological surveys. Positivity in past research could be meaning anything from affirmation of person to displaying hope to positive emotions to laughter, and

\footnotetext{
${ }^{1}$ I used the software Citavi to attach key words to passages. The internal datastructure is accessible through an SQLite interface, that allows for extraction of the keyword tag data into CSV, thereby allowing processing in Excel and R.
} 
depending on different psychological concepts or personality definitions different 'positivities' or listening styles might have very different impacts on friendship maintenance. Thus 'laughter-positivity' (fun) could be different to 'affirmation-see strengths positivity' (affirmation) to 'see positive' positivity (hope, optimism) and points to a clear cost of higher aggregation common in sociological research without a common and clear foundation of definition of concepts. This is not for lack of such, because e.g. the character strengths list employed by Peterson and Seligman, 2004 does lend itself suitably as reference framework for all character related aspects. However as the actual datasets from a number of sociological analyses are not available anymore, salvaging and recycling the data in a general meta study will most likely remain a desideratum.

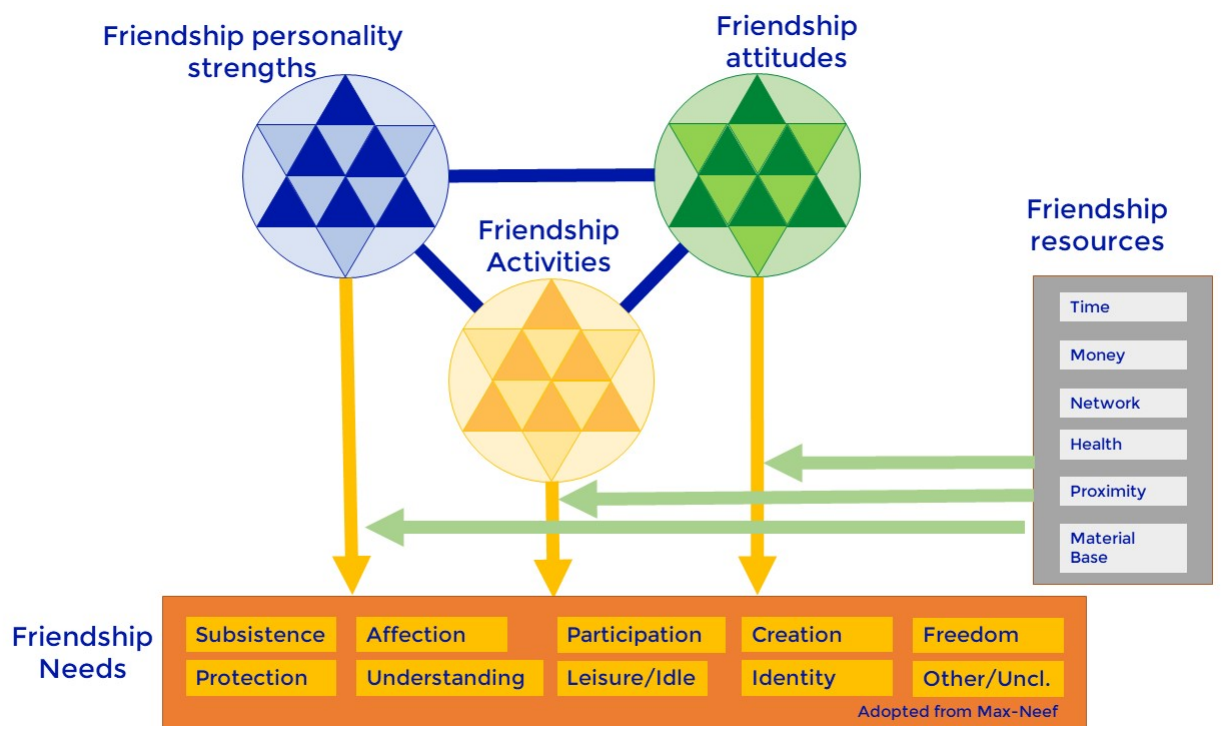

Figure 2. Friendship Framework

\section{The Framework}

The 300 key words were condensed to about 50 characteristics, beyond which further merging felt like merging items that were actually substantially different. These characteristics also fell into three categories of personality traits (like friendship related character strength), relationship attitudes (attributes specific to the relationship of the dyad) and activities.

The personality traits are (1) Patience and Peace, (2) Positivity and hope, (3) Proactiveness and general considerateness, (4) Humility, (5) Social ease and agreeableness, (6) fun and humour, (7) Energy and agency, (8) Honesty and Authenticity, (9) Reliability and consistency, (10) Acceptance and tolerance, (11) kindness and warmth, (12) intelligence and curiosity and (13) virtuous character.

The relationship attitudes can be also dimensions with both ends preferred, this is denoted by 'vs.' rather than 'and'. (1) Respect of Privacy vs. living together, (2) benevolence and care,(3) beneficence and consideration, (4) pride and admiration vs equality, (5) trust and confidentiality, (6) common memory of shared history, (7) mutual belief and background vs different belief and background, (8) loyalty vs independence, (9) mutual interest, (10) mutual understanding, (11) reciprocity and being needed, (12) openness and vulnerability, (13) love and affection and (14) enjoyment of company.

The activities are (1) dirt time, (2) collaboration, (3) deep listening and sharing, (4) encouragement and challenge, (5) exploration and discovery, (6) guidance, (7) practical help, (8) being there for the other, (9) vocal support, (10) effecting change, 
(11) generosity and gifts, (12) teaching and learning, (13) circle bonding and (14) hospitality.

Finally there are eight resources the availability of which can enhance or limit the potential for friendship development: (1) time, (2) material wellbeing, (3) financial resources, (4) network, (5) attractiveness, (6) health and fitness, (7) content and (8) proximity. Essentially resources are all about possibility or relative cost of participating in activities with friends, but the separation is significant, as different items apply to different groups of the population.

The classification of recurring themes of friendships was a result of slow iteration and expansion, as I was grouping and allocating key word themes. Loosely the friendship personality strengths are inspired by the VIA Character Strengths of Seligman, 2004, the friendship attitudes by the general sociological literature (Hall, Adams, Blieszner, Degges-White, Matthews, Oswald and De Vries to name but a few) and the activities by the friendship books such as Shumway, Degges-White and Rath. Sociological research frequently (e.g. in Blieszner and Adams, 1992) wrote also about the exchange of resources, however frequently those resources were disguised personality traits (love, knowledge), and thus I separated just genuine resources that are externally given by the situation. The basis for a category also was not so much the eventual name, such as positivity or understanding, but the collection of 3-5 statements seen to be at the core of this aspect with titles or denominations still very much subject to potential discussion.

Note the distribution of weight to the categories over the entire dataset, with resources only amounting to loosely $5 \%$, and thus the entire weight mostly being split evenly between personality and activities on the one side and relationship attributes on the other.

\begin{tabular}{|c|c|c|c|c|c|c|c|}
\hline Personality \% & 22.9 & Relationship \% & 48.1 & Activities \% & 23.7 & Resource \% & 5.2 \\
\hline Peace & 1.0 & Respect of Priv. & 1.5 & Dirt Time & 4.2 & Time & 0.4 \\
\hline Positivity & 1.4 & Benevolence & 2.3 & Work Together & 2.8 & Material & 0.4 \\
\hline Proactiveness & 1.4 & Consideration & 2.3 & Expression of Self & 2.7 & Money & 0.3 \\
\hline Humility & 2.1 & Pride & 2.4 & Encourage & 1.4 & Network & 0.7 \\
\hline Agreeableness & 1.1 & Trust & 3.0 & Discovery & 1.0 & Attract. & 0.1 \\
\hline Fun & 2.0 & Shared History & 4.5 & Guidance & 1.0 & Health/Athl. & 0.7 \\
\hline Energy & 1.2 & Mutual Belief & 2.0 & Pract. Help & 2.0 & Content & 0.9 \\
\hline Honesty & 3.5 & Loyalty & 3.5 & Being there & 2.7 & Proximity & 1.3 \\
\hline Reliability & 2.0 & Mut. Interest & 2.2 & Vocal Support & 0.6 & NoMonPower & 0.5 \\
\hline Acceptance & 2.2 & Understanding & 3.1 & Effect Change & 1.2 & & \\
\hline Kindness & 1.8 & Reciprocity & 3.0 & Generosity & 0.7 & & \\
\hline Intelligence & 1.6 & Openness & 2.6 & Teach \& Learn & 0.8 & & \\
\hline \multirow[t]{7}{*}{ Virtue } & 1.7 & Affection & 2.8 & Circle & 1.5 & & \\
\hline & & Enjoyment & 3.4 & Communion & 1.2 & & \\
\hline & & Independence & 1.5 & & & & \\
\hline & & NindRespPriv & 0.5 & & & & \\
\hline & & DiffBG & 0.2 & & & & \\
\hline & & FS Priority & 3.6 & & & & \\
\hline & & FS Quality & 3.7 & & & & \\
\hline
\end{tabular}

Figure 3. Total Summary

\section{Clustering}

As currently only 40 sources are coded with $50+$ variables classical methods of factor analysis or principal component analysis do not work well to extract information. What does generate results is the mining algorithm of K-Means, with both Euclidean and Manhattan Distance to account for weights of significant outliers. Some degree of Winsorization could also be applied for the same purpose. Applying K-Means with Euclidean Distance to the current dataset places CS Lewis into one cluster and Bible \& Christian writings into another, and then distributing the other Authors into remaining three clusters, loosely described as one utilitarian (Rath, Birch and MBTI), 
another joined philosophical (Aristotle, Cicero, Alberoni, Cuddeback)and sociological (Millington, Hall) cluster, and another purely sociological portfolio (DeggesWhite, Shumway, Nelson, Adams and Blieszner). However these are not stable, indeed shifted between 6000 and 9000 key words and a future version will most likely generate slightly different groupings with then also adjusted centroids. As further sources get added in, and also subgroups such as texts specifically written to or about young or old, male or female people get added, analysing friendship preferences will become less sensitive to individual texts or observations.

A good method for illustrating the connections is that of graphing using dimension reduction techniques such as multidimensional scaling by Mead, 1992. There are suitable R-packages available including, and the figures are generated with the general cmdscale functionality as well as the igraph package. 4 and 5 show connections between the key properties and the authors respectively. At the 10000 word mark these were reasonably robust to omissions of outliers and a general theme is emerging on both counts. While the Author connections are in line with the k-means clustering, the clustering of the properties is quite illustrative and hints at the existence of a few key dimensions.

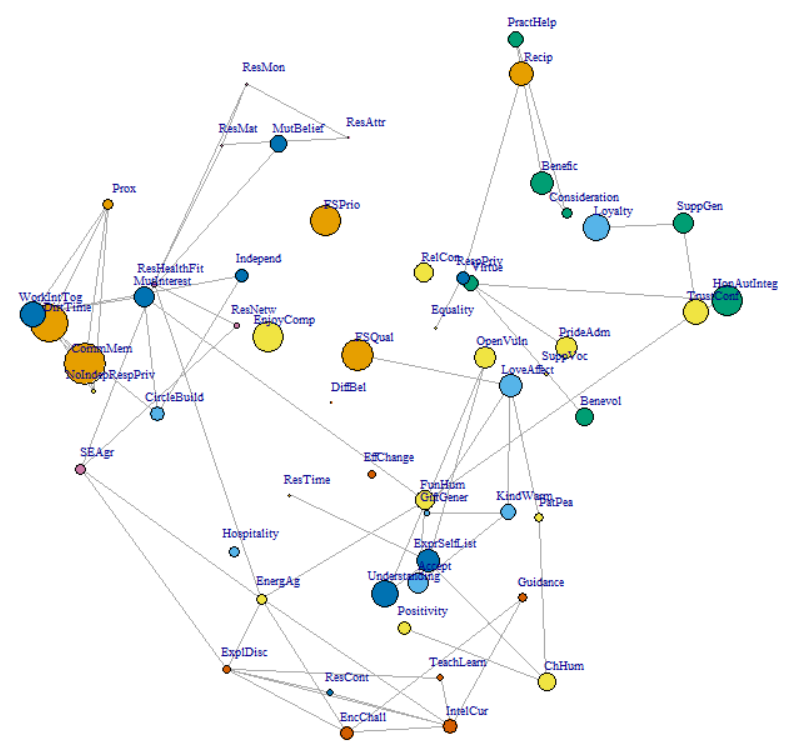

Figure 4. Property Connections

(1) Common Time: Dirt Time, Proximity, No Respect for Privacy, Common History and Memory, and interestingly also Reciprocity

(2) Affection and Care: Valuing the relationship, Loyalty, Admiration, Affirmation, Kindness and warmth, Hospitality and Communion, Love and Affection

(3) The classical canon: virtuous character, benevolence, beneficence, meeting each others needs, practical help

(4) Good relationship practice: Positivity, Humility, Reliability, Consistency, Openness, Vulnerability, Trust and Confidentiality, Enjoyment and Leisure, Fun and Humour

(5) Collaboration and Understanding: Work Together, Similar belief, Expression of self and deep listening 


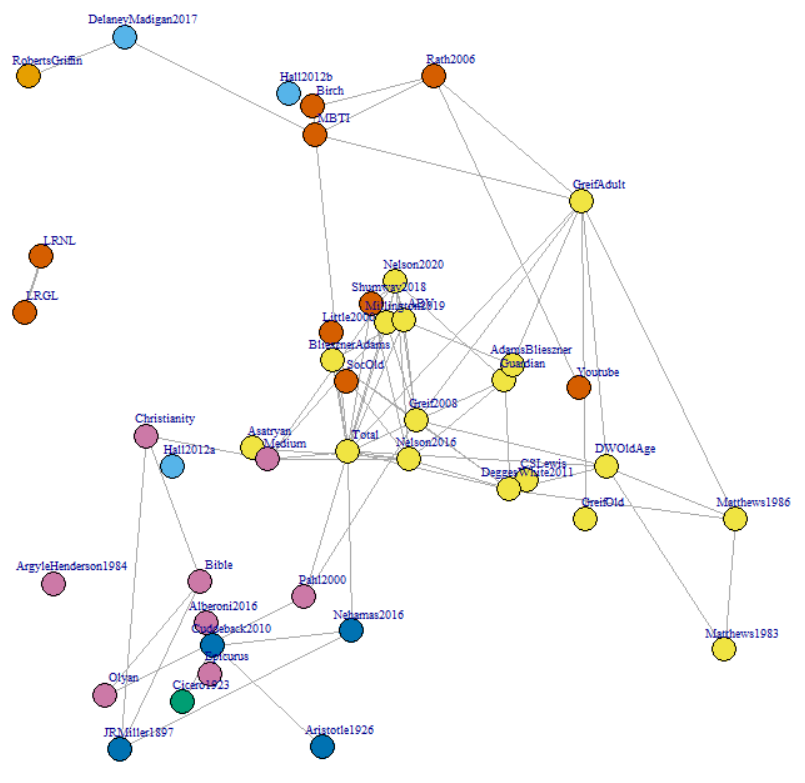

Figure 5. Author Connections

(6) Improvement: Exploration and Discovery, Encourage and Challenge, Guidance Direction, Intelligence and Curiosity, Resource Content

(7) (Resources): Money, Health, Mobility and Material base came off as a separate factor with minor weight or are classed with collaboration.

(8) (Privacy): Respect of Privacy, Independence within Friendship

It is at this point that it also makes sense to propose a concept of friendship needs. Assuming that we pursue friendships because these satisfy functional needs of ours we can ask ourselves of what nature these needs are. On the back of the excellent summary of human development scales in Alkire, 2002 and her given criteria on how to evaluate them, I tried out a few of them that were focused on psychological needs rather than the general measures of poverty and human development. The framework of Max-Neef, Elizalde, and Hopenhayn, 1992 provided the most natural fit with its categories of subsistence, protection, affection, understanding, participation, leisure, creation, identity and freedom. Natural here I mean the degree to which common sense and intuition provided a natural fit when trying to map the correspondence of friendship key words to the need categories. Intuitively I found the categorization almost like a perfect descriptions of 'love languages for friendship'(in exactly the same sense that Chapman, 2009 writes about love languages for romantic couples the frequencies on which signals of love are both sent and received, if the partner is open for reception). It should be noticed of course that this concept of 'friendship satisfying a need' or 'friendship being a need to be satisfied' is strongly argued against in Alberoni, 2016. Evidence for the possibility of satisfying this need is provided by evolutionary biology and general psychological research, and its tradition ranges to Aristotle (Humans are social animals) and arguably the earliest part of the Bible (it is not good for man to be alone ...). I would argue that it is a bit of both. Individual 'low-level' needs can be satisfied, in the sense that some people can be made to feel good (and some absolutely fantastic) simply by spending some time with their friends over a hike. For other aspects, in particular questions of meaning or identity, the long term effect is important. A further tangent is the fundamental nature of these needs. Yalom, 1980 in his reference work describes four ultimate concerns 
as fundamental psychological questions that every person needs to answer for her or himself: Death, Isolation, Freedom and Meaninglessness. In a way partitioning the above terminology into short-term affective (Subsistence, Protection, Affection, Leisure), transcendent (Creation, Identity, Freedom) and in-between (Understanding, Participation), it can be seen that the transcendent and in-between friendship needs directly cater to the needs of isolation-Connectedness (participation, understanding), freedom-responsibility (freedom), and meaning (identity, creation).

\begin{tabular}{|c|c|c|c|c|c|c|c|c|}
\hline & Subs + Prot & Affection & Understanding & Participation & Leisure/Idleness & Creation & Identity & Freedom \\
\hline Common Time & 0.38 & 0.10 & 0.23 & 0.87 & 0.20 & 0.64 & -0.33 & 0.15 \\
\hline Affection / Care & 0.02 & 0.50 & 0.13 & 0.15 & 0.01 & 0.04 & $-\quad 0.02$ & 0.16 \\
\hline Classics & 0.61 & 0.26 & 0.04 & 0.50 & 0.33 & 0.13 & 0.68 & 0.08 \\
\hline Good Rel & 0.19 & 0.49 & 0.16 & 0.51 & 0.42 & 0.26 & 0.13 & 0.57 \\
\hline Collaboration Understanding & 0.43 & 0.32 & 0.13 & 0.25 & 0.08 & 0.39 & $-\quad 0.37$ & 0.65 \\
\hline Improvement & 0.20 & 0.22 & 0.84 & 0.35 & 0.08 & 0.32 & 0.14 & 0.03 \\
\hline Resource & 0.21 & 0.34 & 0.19 & 0.31 & 0.27 & 0.00 & - $\quad 0.35$ & 0.08 \\
\hline
\end{tabular}

Figure 6. Correlations Factors and Needs

Whilst some factors naturally correspond to some of the needs listed above, there is no 1-1 correspondence, as figure 6 shows, and thus conceptually it seems currently necessary to keep the friendship factors and the needs separate. The correlational graph however shows very clearly also the differences in emphasis that can occur, depending which friendship model and addressable need the author thinks is key. Furthermore a further reduction from the seven factors or the eight needs will come at a cost of goodness of fit. The Graphs in the appendix show furthermore that while for some needs clusters do have common themes (e.g. the self help books commonly emphasising affection, and old age sources emphasising participation) on some dimensions there is wide within cluster spread. Thus among the philosophers or sociologists the importance of Understanding varies widely, or the role of subsistence and protection diverges for philosophers and religious sources. This divergence is likely to also occur when going out to survey people for their friendship preferences and habits when given the full spectrum of possibilities.

\section{Friendship Process}

Resulting from this set of personality traits, relationship attitudes and activities it is possible to take Aristoteles original goodwill and virtue based definition of friendship and generalise it. 'Friendship is a free relationship of two or more people, (1) who bring into the friendship some personality strengths conducive to forming a relationship and attractive to the respective other, (2) who develop an attitude to, appreciation and understanding of each other through past interactions, and (3) who repeatedly act out their friendship with and towards each other through a variety of activities.' Fischer, 1982, p.289 makes the claim to report observations, i.e. correlations but no causalities ${ }^{2}$ Fehr, 1996 describes friendship development processes at great length, though for the purpose of this definition it is a start to note that both 'Friendship by Spark' style or the 'Takes time to Grow' friendship are proposed as natural in literature. It is thus not easy to decide whether the existence of friendship determines the attitude and activities, or whether activities and a developing attitude builds and develops the friendship.

\footnotetext{
2, And no causal claims are made, only claims of correlation. The fact that associates with whom respondents discussed their hobbies were especially likely to be called friends could mean that discussing hobbies determines whether an associate will be called a friend, or it could mean that respondents were especially likely to turn to people they called friends when they wanted to discuss their hobbies. Either causal interpretation would be appropriate.'
} 


\section{Friendship in Old Age}

This is now the part where this analysis moves from being theoretically interesting to potentially applicable and useful. Thinking about the idea on how to foster friendships in the third age in order to reduce loneliness, it is necessary to ask the question, what kind of friendships elderly would like to have, and what needs need to be addressed. Utilizing the datasets provided by the coding of Degges-White and Borzumato-Gainey, 2011. Ch10, Greif, 2009, Ch11-14, Matthews, 1983 and Adams and Blieszner, 1989 we have a combined dataset of 734 tags of friendship in old age, and can in figure 7 calculate multiples relative to total dataset average displayed in figure 3 Starting with needs it becomes clear that old people are mostly concerned with participation, still being part of society. On the other hand they have lived their lives and do not need so much to refine their character and identity as the young ones. We can deduce that resources (in the classical sense) become much more important in old age than during earlier years. Financial constraints determine the capacity to participate in cultural activities, as does health. This all correlates with mobility (being able to go about to see people) as well as proximity (how far I need to go to see friends). The general goal is to spend a good and enjoyable time with each other, in a circle of agreeable people who can appreciate their history, ideally old friends with whom they can indulge in nostalgia. A curious fact is the insistence on respect of privacy as well as contrary to that the wish that people would less insist on privacy and be withdrawn (NIndRespPriv), but come out, open their houses, eat and live closer to each other. Finally there is a desire to enjoy mutual interests and hobbies together and be thus somewhat productive (WorkTogether).

\begin{tabular}{|c|c|c|c|c|c|c|c|c|c|c|c|}
\hline & $\mathrm{OA}$ & Tot & & $O A$ & Tot & & $O A$ & Tot & & $O A$ & Tot \\
\hline Personality \% & 15.2 & 22.9 & Relationship \% & 47.7 & 48.1 & Activities \% & 26.9 & 23.7 & Resource \% & 10.1 & 5.2 \\
\hline Honesty & 1.5 & 3.5 & Shared History & 6.8 & 4.5 & Dirt Time & 7.6 & 4.2 & Proximity & 3.2 & 1.3 \\
\hline Acceptance & 1.5 & 2.2 & Affection & 3.2 & 2.8 & Work Together & 4.5 & 2.8 & Content & 1.0 & 0.9 \\
\hline Humility & 1.1 & 2.1 & FS Quality & 3.7 & 3.7 & Expression of S & 2.9 & 2.7 & Health/Athl. & 1.7 & 0.7 \\
\hline Reliability & 1.2 & 2.0 & Consideration & 1.0 & 2.3 & Being there & 2.3 & 2.7 & Network & 0.6 & 0.7 \\
\hline Fun & 1.1 & 2.0 & FS Priority & 4.1 & 3.6 & Pract. Help & 2.3 & 2.0 & Time & 0.5 & 0.4 \\
\hline Kindness & 1.4 & 1.8 & Loyalty & 2.2 & 3.5 & Circle & 1.9 & 1.5 & Material & 2.0 & 0.4 \\
\hline Virtue & 1.1 & 1.7 & Independence & 1.6 & 1.5 & Encourage & 0.7 & 1.4 & Money & 0.7 & 0.3 \\
\hline Intelligence & 1.4 & 1.6 & Enjoyment & 3.2 & 3.4 & Communion & 1.2 & 1.2 & NoMonPower & 0.3 & 0.5 \\
\hline Positivity & 0.8 & 1.4 & Understanding & 2.6 & 3.1 & Effect Change & 0.6 & 1.2 & Attract. & 0.1 & 0.1 \\
\hline Proactiveness & 0.6 & 1.4 & Reciprocity & 2.9 & 3.0 & Guidance & 0.9 & 1.0 & & & \\
\hline Energy & 1.3 & 1.2 & Trust & 2.2 & 3.0 & Discovery & 0.8 & 1.0 & & & \\
\hline Agreeableness & 1.8 & 1.1 & Openness & 1.4 & 2.6 & Teach \& Learn & 0.4 & 0.8 & & & \\
\hline \multirow[t]{7}{*}{ Peace } & 0.5 & 1.0 & Pride & 1.4 & 2.4 & Generosity & 0.5 & 0.7 & & & \\
\hline & & & Benevolence & 1.7 & 2.3 & Vocal Support & 0.2 & 0.6 & & & \\
\hline & & & Mut. Interest & 2.7 & 2.2 & & & & & & \\
\hline & & & Mutual Belief & 3.9 & 2.0 & & & & & & \\
\hline & & & DiffBG & 0.3 & 0.2 & & & & & & \\
\hline & & & Respect of Priv. & 1.6 & 1.5 & & & & & & \\
\hline & & & NindRespPriv & 1.2 & 0.5 & & & & & & \\
\hline
\end{tabular}

Figure 7. Friendship in Old Age

\section{Further Research}

As the main thrust of this venture is to identify how friendships can be strengthened in midlife so that in later life loneliness is reduced, this theoretical construct needs to be validated. It is unlikely that truly common themes appear. Friendship is by its nature very individual, and friends as Rath, 2006 noticed play different roles to each other. It would be thus great to validate and quantify what needs which groups of people have both in midlife and elder life, and then to see whether there can be interventions to gently nudge people as a whole to interact in meaningful ways that build the friendships towards each other tailored to these needs.

For me the major takeaway is the loss of information and depth, that attempts to reduce friendship to a two, three, four or six factor model and validate them with various survey and statistical methods incur. Friendship is a nuanced relationship, 
probably significantly more nuanced than romantic relationships, and needs to be treated as much. Characteristics or aspects that are crucial to one person could be negligible to the next. Reducing friendship quality to a set of one to three questions on social support, emotional sharing, discussing personal items or joint activities as is common practice in public surveys is likewise falling short of many peoples diverse understanding of what friendship means to them. The need for such procedure in the context of large scale population surveys is of course self-evident, but for genuine research of the causes of loneliness the specific dimension in which people feel lonely (i.e. the friendship 'need') probably is a crucial ingredient of the analysis.

Before putting this to proper and practical use there is the question of how to validate the stability of the individual items further, and measure how each of the factors are influenced by age, gender, culture etc., and in turn impact friendship satisfaction. This will happen as more and more texts on friendship are worked through in the above described manner, as well as preparing a survey study to corroborate on a larger scale the relative significance that the literature above implied.

A lot of past sociological research while trying to identify general social mechanisms on the general concept of self disclosure or support did use very specific questions to measure disposition for it, see Hall, 2012 for such a list. It thus should be possible to recode and thus utilize a lot of past research for integration into the variable set described above. Unfortunately open data policies only have become popular in the last five to three years, and it will be interesting how much data can genuinely be salvaged from past surveys and studies for this meta study. The rewards however can potentially be great, ideally generating insight on how to enhance and strengthen friendships on a character, gender, age or other trait configuration.

Furthermore - while romantic relationships or general family relationships are substantially and structurally different in structure than friendships, a survey could likewise be conducted on how family members score on these scales and importance, and in what aspects significant differences occur to friendships. This would also provide additional evidence to the debate of whether friendships and kinships are complementary, substitutable or to what degree they can and do overlap.

\section{CONCLUSiON}

This is a reasonable framework to analytically categorize friendships and in particular friendship activities within the larger project 'Maintaining Friendships in Midlife'. It brings together philosophical, psychological, sociological and popular contemporary material, and thus shows agreements and contrarian points. Whilst it draws on a lot of survey- or data based material, it is not yet validated by a comprehensive survey.

Given the variety of different dimensions, and the peril of missing a significant part of the picture, the paper is useful in showing the difficulty of defining friendship by its properties such as Freedom of Choice, Reciprocity, Affection, Loyalty or others. A general definition is necessary, which however will have to acknowledge that for individual people it will always be broken down to specific properties individually and possibly individual to the specific relationship. It should also encourage future researchers on friendship to take the topic on holistically, and not just quote selectively from authors of young and old to support points they prefer and ignore inconvenient corollaries 3

At the point of this writing (March 4, 2021) this document is just a proposition for discussion and testing to be developed over the course of 2020. At the time of this publication about 10000 key words are included, and texts for another $\approx 4000$ key words are still to be covered. For actual publication it will be edited for brevity. Please feel free to contact me with suggestions and comments.

\footnotetext{
${ }^{3}$ For me the stereotype is that of Aristotle postulating friends to live together, Ciceronian brutal honesty when required, Jesus disciples sharing wealth - as pointed out by Fromm, 2013 biblical loyalty, or the simple realisation that while having friends is wonderful, it does cost time, attention and effort on one's own behalf
} 


\section{APPENDIX}

\section{REFERENCES}

Adams, R.G. and Blieszner, R., eds, 1989. Older adult friendship: Structure and process. Vol. 103. SAGE Publications, Incorporated.

Alberoni, F., 2016. Friendship [Online]. Vol. 20, Social and Critical Theory. Brill. Available from: https://doi.org/10.1163/9789004331303.

Alkire, S., 2002. Dimensions of human development. World development, 30(2), pp.181205.

Apostolou, M. and Keramari, D., 2020. What prevents people from making friends: A taxonomy of reasons. Personality and Individual Differences, 163, p.110043.

Apostolou, M., Keramari, D., Kagialis, A., and Sullman, M., 2020. Why people make friends: The nature of friendship. Personal Relationships.

Argyle, M. and Henderson, M., 1984. The Rules of Friendship. Journal of Social and Personal Relationships, 1, pp.211-237.

Aristotle, 1926. Nicomachean Ethics: Translation by Rackham [Online]. Loeb Classical Library, Harvard University Press, Cambridge, MA. Available from: http://data. perseus.org/citations/urn: cts:greekLit:tlg0086.tlg010.perseus-eng1: 9.1.

Asatryan, K., 2016. Stop Being Lonely. New World Library.

Birch, J., 2018a. Myers Briggs Compatibility for Friends [Online]. Available from: https : //www .manrepeller . com/2018/03/myers-briggs-compatibility-forfriends.html [Accessed June 27, 2020].

Birch, J., 2018b. What you need from your friends [Online]. Available from: https: //boldl . com/blogs /man-repeller/what-you-need-from-your-friendsaccording-to-your-myers-briggs.

Birch, J., 2019. Good Friends Are Hard to Come by-Here's What to Look for in One, According to Your MBTI Profile.

Blieszner, R. and Adams, R.G., 1992. Adult friendship. Vol. 3. Sage Publications.

Blieszner, R., Ogletree, A.M., and Adams, R.G., 2019. Friendship in Later Life: A Research Agenda. Innovation in Aging [Online], 3(1). Available from: https:// doi.org/10.1093/geroni/igz005.

Cerri, 2019. The Myers Briggs Types That Make The Best (And Worst) Friends [Online]. Available from: https : / / www . yourtango . com/2019321764/myers briggs-types-make-best-and-worst-friends-ranked-best-worst [Accessed June 27, 2020].

Chapman, G., 2009. The Five Languages Singles Edition. Northfield.

Cicero, M.T., 1923. De Amicitia: Retrieved under CC BY-SA licence [Online]. Loeb Classical Library, Harvard University Press, Cambridge, MA. Available from: http: //www . perseus . tufts. edu/hopper/text?doc=Perseus : text : 2007.01 .0052

Degges-White, S. and Borzumato-Gainey, C., 2011. Friends forever: How girls and women forge lasting relationships. Rowman \& Littlefield.

Delaney, T. and Madigan, T., 2017. Friendship and happiness: And the connection between the two. McFarland. 
Deri, S., Rappaz, J., Aiello, L.M., and Quercia, D., 2018. Coloring in the links: Capturing social ties as they are perceived. Proceedings of the ACM on Human-Computer Interaction, 2(CSCW), pp.1-18.

Fehr, B., 1996. Friendship processes. Vol. 12. Sage.

Fischer, C.S., 1982. What do we mean by 'friend'? An inductive study. Social Networks, 3(4), pp.287-306.

Fromm, E., 2013. To have or to be? A\&C Black.

Greif, G., 2009. Buddy System - Understanding Male Friendships. Oxford University Press.

Hall, J.A., 2012. Friendship Standards: The dimensions of ideal expectations. Journal of Social and Personal Relationships.

Lewis, C.S., 1960. The Four Loves: The Four Loves by CS Lewis C) copyright CS Lewis Pte Ltd 1960. Used with permission. Geoffrey Bles.

Matthews, S.H., 1983. Definitions of Friendship and their Consequences in Old Age. Ageing and Society [Online], 3(2), pp.141-155. Available from: https://doi.org/ 10.1017/S0144686X00009983.

Matthews, S.H., 1986. Friendships through the life course: Oral biographies in old age. Vol. 161. SAGE Publications, Incorporated.

Max-Neef, M., Elizalde, A., and Hopenhayn, M., 1992. Development and human needs. Real-life economics: Understanding wealth creation, 197, p.213.

Mead, A., 1992. Review of the development of multidimensional scaling methods. Journal of the Royal Statistical Society: Series D (The Statistician), 41(1), pp.2739.

Millington, C., 2019. The Friendship Formula. Croydon: Head of Zeus Ltd.

Nehamas, A., 2016. On Friendship. Basic Books.

Nelson, S., 2016. Frientimacy. Seal Press.

Nelson, S., 2020. The Business of Friendship. Harper Collins.

Oswald, D., Clark, E., and Kelly, C., 2004. Friendship Maintenance: An Analysis of individual and dyad behaviours. Journal of Social and Clinical Psychology.

Peterson, C. and Seligman, M., 2004. Character Strengths and Virtues. Oxford University Press.

Rath, T., 2006. Vital Friends. Gallup Press.

Roberts-Griffin, C.P., 2011. What is a good friend: A qualitative analysis of desired friendship qualities. Penn McNair Research Journal, 3(1), p.5.

Seligman, M., 2004. Authentic Happiness. Atria Books.

Shumway, K., 2018. The Friendship Formula. Kyler Shumway.

van Devender, E., 2020. The Kind Of Friend You Are, According To Your MyersBriggs Personality Type \& Traits [Online]. Available from: https://www yahoo. com/lifestyle/type-friend-according-myers-briggs-061634055.html.

Yalom, I., 1980. Existential Psychotherapy. Basic Books. 


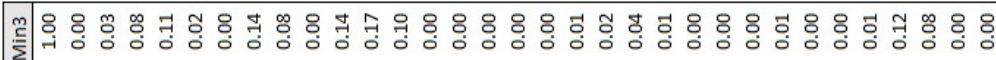

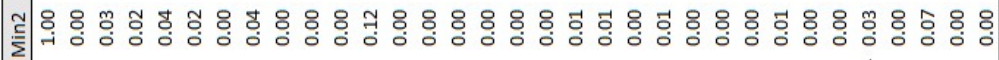

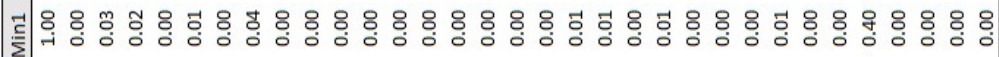



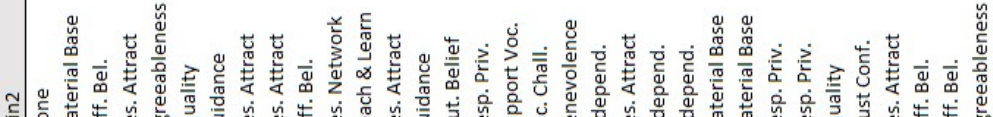

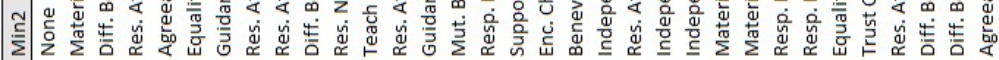

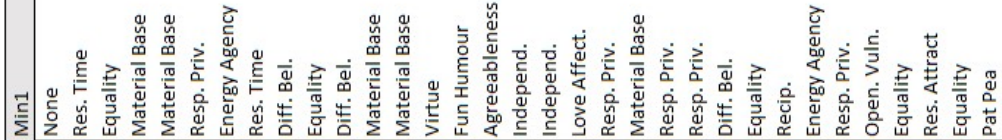

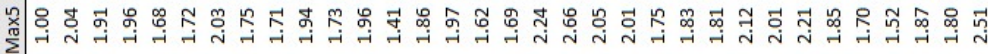



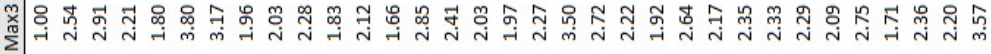

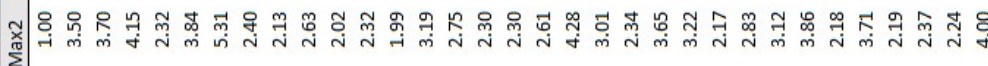



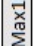

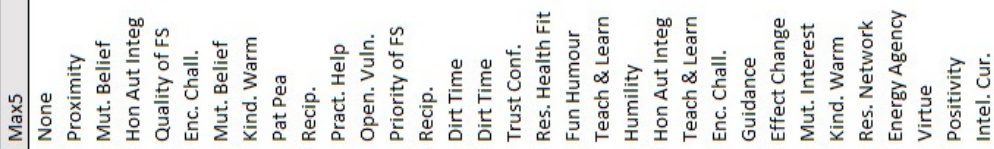

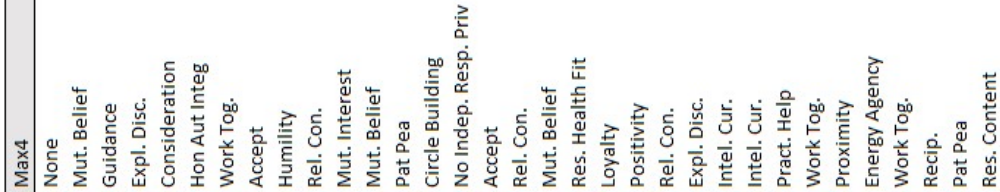

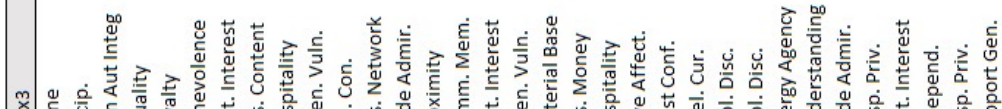

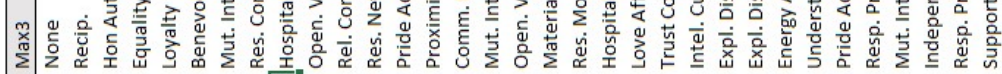

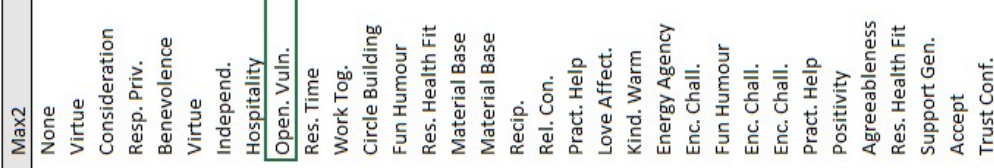

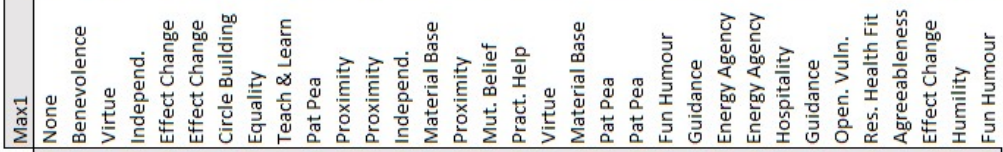

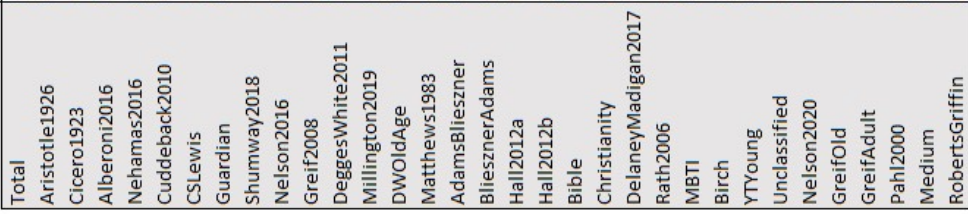




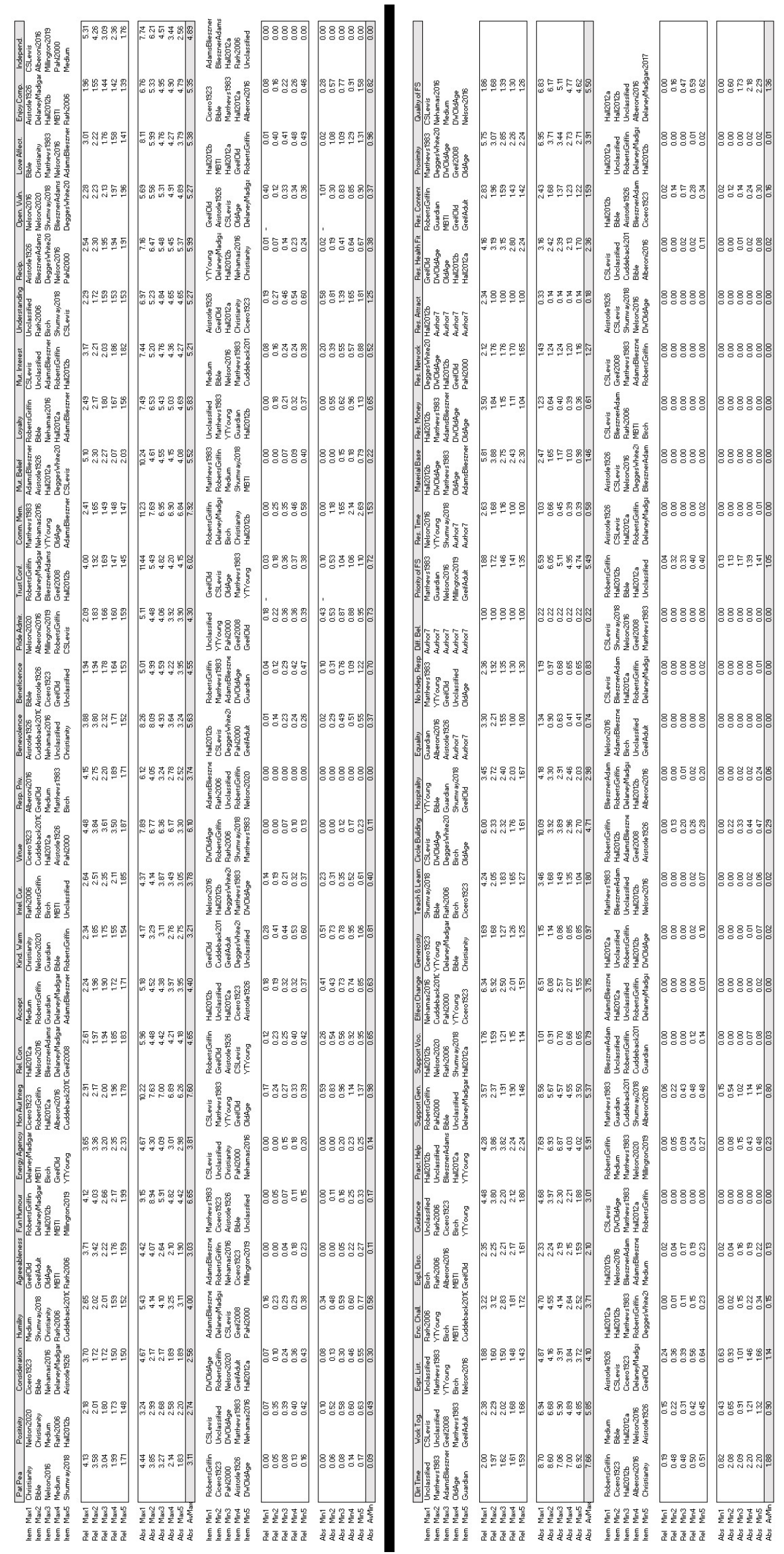


Permanent: Christian Langkamp, Am Bilderstock 10, 41352 Korschenbroich, Germany

Email address: christian.langkamp @ outlook.com

$U R L$ : www.practicalfriendship.com for project overview and survey hosting 